\title{
Urinary felinine excretion in intact male cats is increased by dietary cystine
}

\author{
Wouter H. Hendriks ${ }^{1}$, Kay J. Rutherfurd-Markwick ${ }^{2}$, Karin Weidgraaf ${ }^{2}$, R. Hugh Morton ${ }^{2}$ \\ and Quinton R. Rogers ${ }^{3}$ \\ ${ }^{1}$ Animal Nutrition Group, Department of Animal Sciences, Wageningen University, Wageningen, The Netherlands \\ ${ }^{2}$ Institute of Food, Nutrition and Human Health, Massey University, Palmerston North, New Zealand \\ ${ }^{3}$ Department of Molecular Biosciences, University of California, Davis, CA, USA
}

(Received 22 August 2007 - Revised 22 January 2008 - Accepted 23 January 2008 - First published online 17 March 2008)

Felinine is a branched-chain sulfur amino acid present in the urine of certain Felidae, including domestic cats. The objective of the present study was to determine if additional cystine and/or dietary $N$ would increase felinine and $N$-acetylfelinine excretion by intact male cats fed a low-protein (LP) diet. Feeding five adult intact male cats an LP diet (18.8\% of metabolisable energy (ME) as protein) $v$. a high-protein diet (38.6\% of ME as protein) resulted in a trend $(P=0.08)$ for decreased urinary felinine and no change in $N$-acetylfelinine excretion. In a $23 \mathrm{~d}$ study, when the LP diet was supplemented with L-cystine at $9.3 \mathrm{~g} / \mathrm{kg}$ DM, urinary felinine:creatinine ratio showed a linear two-fold (121 \%) increase $(P<0 \cdot 01)$ from $0 \cdot 24$ (SEM 0.05) to 0.53 (SEM 0.13) after $10 \mathrm{~d}$. Subsequent feeding of the LP diet resulted in a decrease in felinine excretion to base levels. Plasma $\gamma$ glutamylfelinylglycine concentrations were consistent with the excretion of felinine. Supplementation of the LP diet with L-cystine (9.3 g/kg DM), dispensable amino acids and arginine to a second group $(n 5)$ also resulted in a significant $(P<0 \cdot 01)$ but smaller $(+72 \%)$ increase in the daily felinine:creatinine ratio $(0.25$ (SEM 0.04$)$ to 0.43 (SEM 0.05)). The degree of felinine $N$-acetylation within groups was unaffected by dietary addition and withdrawal of amino acids. The results indicate that felinine synthesis is regulated by cystine availability, and that arginine may be physiologically important in decreasing felinine biosynthesis in intact male cats.

$N$-acetylfelinine: Arginine: Cats: Cysteine: Felinine

Felinine is a unique amino acid excreted by certain species within the Felidae family, including the domestic cat. This sulfur-containing, branched-chain amino acid has been found in concentrations of $3.6 \mathrm{~g} / \mathrm{l}$ in the urine of intact male cats (Felis catus), with castrated males excreting approximately one-quarter as much as intact males ${ }^{(1)}$. Synthesis of felinine is believed to occur from glutathione and isopentenylpyrophosphate, through a unique glutathione sulfur transferase enzyme which is under hormonal control ${ }^{(2,3)}$ to form a felinine-containing tripeptide: $\gamma$-glutamylfelinylglycine or methylbutanolglutathione (MBG). The $\gamma$-glutamylfelinylglycine is transported in the blood ${ }^{(4)}$ to the kidney where hydrolysis by $\gamma$-glutamyltransferase present on the surface of the brushborder membrane of proximate tubular cells results in felinylglycine and glutamic acid. The dipeptide can be further hydrolysed to felinine and glycine by either dipeptidase activities or a recently discovered enzyme with carboxylesterase activity $^{(5)}$. This $70 \mathrm{kDa}$ enzyme (cauxin) has been found in relatively high concentrations in feline urine and has been shown to be able to hydrolyse felinylglycine but not $\mathrm{MBG}^{(5)}$. Following the hydrolysis of felinylglycine, $N$-acetylation of felinine can occur. This is an intracellular process catalysed by cysteine-S-conjugate $\mathrm{N}$-acetyltransferase and yielding mercapturic acids via the addition of an acetyl group transferred from acetyl-CoA, which are subsequently excreted in the urine.

Dietary supplementation of $1 \%$ cysteine to a nominal cysteine $(0.5 \%)$ diet has been shown to significantly increase whole blood glutathione concentrations from approximately 4.15 to $4.5 \mu \mathrm{mol} / \mathrm{g} \mathrm{Hb}$ in castrated male and female cats ${ }^{(6)}$. Urinary felinine excretion in intact male cats has been shown to increase from $1.5 \mathrm{~g} / \mathrm{l}$ to over $8 \mathrm{~g} / \mathrm{l}$ within $3 \mathrm{~d}$ following the supplementation of the diet with $1 \%$ L-cystine $^{(7)}$; unfortunately the authors failed to report total felinine excreted per d. Clearly, the extent of the increase in glutathione concentration is small (approximately 10\%) compared with that of felinine $(433 \%)$.

From the above studies as well as our own previous work demonstrating that cysteine is a more immediate precursor to felinine than methionine ${ }^{(8)}$, we hypothesised that felinine synthesis would be increased by feeding a high-protein (HP) diet compared with one with low protein (LP). The results from this study (reported here as study 1) did not support this hypothesis and a subsequent study was designed to test the effect of cystine supplementation on felinine excretion.

Therefore, the main aims of the studies reported here were to determine the effects of (1) dietary protein level

Abbreviations: BW, body weight; cys + met, cystine + methionine; HP, high-protein; LP, low-protein; LPc, low-protein + cystine; LPc + D + arg, low-protein + cystine + dispensable amino acids + arginine; MBG, methylbutanolglutathione; ME, metabolisable energy.

* Corresponding author: Dr W. H. Hendriks, fax +31317484260, email wouter.hendriks@wur.nl 
on urinary felinine and $\mathrm{N}$-acetylfelinine excretion and (2) the addition of cystine and dispensable amino acids on the concentration of felinine and $\mathrm{N}$-acetylfelinine in the urine and the felinine precursors (cysteine, methionine, glutathione and MBG) in the blood of cats fed an LP diet.

\section{Materials and methods}

\section{Animals and housing}

Intact adult male domestic short-haired cats (1.3-6 years old) from Massey University's Centre for Feline Nutrition (Palmerston North, New Zealand) were used in two studies. The body weight (BW) of the cats at the beginning of the two studies was 3.52 (SEM 0.14) kg. Each cat had been vaccinated against feline rhinotracheitis, calicivirus and panleukopenia using a modified live vaccine (Felocell CVR; Norden Laboratories, Munich, Germany). The cats used in this experiment had been raised since weaning predominantly on moist commercial diets similar in composition to the HP diet described in Table 1. Throughout the study, the cats were housed in metabolism cages in a covered shelter at ambient temperatures (average minimum-maximum, $14-22^{\circ} \mathrm{C}$ ), allowing the quantitative collection of uncontaminated urine ${ }^{(9)}$, and had fresh water available at all times. Food was also provided ad libitum and was supplied fresh once per $\mathrm{d}$. The studies reported here were approved by and conformed to the requirements of the Massey University Animal Ethics Committee ${ }^{(10)}$

Table 1. Ingredient composition of the four experimental diets

\begin{tabular}{|c|c|c|c|c|}
\hline \multirow[b]{2}{*}{ Ingredient } & \multicolumn{4}{|c|}{ Diet (g/kg as-is) } \\
\hline & $\mathrm{HP}$ & LP & LPc & $\mathrm{LPc}+\mathrm{D}+\arg$ \\
\hline Canned diet* & $1000 \cdot 0$ & 780.9 & 780.9 & 780.9 \\
\hline Starch & - & 144.9 & 141.6 & 102.0 \\
\hline Lard & - & 63.0 & 63.0 & 63.0 \\
\hline $\begin{array}{l}\text { Dispensable amino } \\
\text { acids mixture }\end{array}$ & - & - & - & $36 \cdot 0$ \\
\hline L-Cystineł & - & - & 3.3 & $3 \cdot 3$ \\
\hline L-Arginine§ & - & - & - & 3.6 \\
\hline $\begin{array}{l}\text { Vitamin-mineral } \\
\text { premix\| }\end{array}$ & - & $11 \cdot 2$ & $11 \cdot 2$ & $11 \cdot 2$ \\
\hline \multicolumn{5}{|c|}{$\begin{array}{l}\text { Determined metabolisable } \\
\text { energy }\end{array}$} \\
\hline $\mathrm{kJ} / \mathrm{g} \mathrm{DM}$ & $20 \cdot 2$ & $16 \cdot 3$ & & \\
\hline $\mathrm{kcal} / \mathrm{g} \mathrm{DM}$ & 4.83 & 3.90 & & \\
\hline
\end{tabular}

HP, high-protein; LP, low-protein; LPc, low-protein + cystine; LPc + D + arg, LPc + dispensable amino acids + arginine.

* Ingredients list: meat by-products and meat derived from lamb, beef, chicken and mutton, vegetable protein, gelling agents, Ca supplement, phosphate, colouring and essential vitamins. Analysed composition (g/kg DM): crude protein, 530; crude fat, 313; ash, 95; cystine, 5.2; methionine, 9.6; arginine, 27.6; glutamic acid, 58.0; glycine, 37.4; proline, 28.5; taurine, 1.56 . Water content: $818 \mathrm{~g} / \mathrm{kg}$ as-is.

†Dispensable amino acid mixture contained $(\mathrm{g} / \mathrm{kg})$ : L-glutamic acid, 500; L-glycine, 250; L-proline, 250.

‡L-Cystine, Sigma Grade, Sigma-Aldrich, Inc. (St Louis, MO, USA).

$\S \mathrm{L}$-Arginine (free base) (Ajinimoto, Japan).

\| Provided to the diet (per kg): Ca, $4.7 \mathrm{~g} ; \mathrm{P}, 3.6 \mathrm{~g} ; \mathrm{K}, 2.3 \mathrm{~g}$; choline, $1.4 \mathrm{~g} ; \mathrm{Cl}, 0.6 \mathrm{~g}$; $\mathrm{Na}, 0.3 \mathrm{~g} ; \mathrm{Mg}, 0.2 \mathrm{~g}$; taurine, $340 \mathrm{mg}$; inositol, $125 \mathrm{mg}$; Fe, $45 \mathrm{mg} ; \mathrm{Zn}, 42 \mathrm{mg} ; \mathrm{Cu}$, $4.5 \mathrm{mg}$; Mn, $4.3 \mathrm{mg}$; I, $0.6 \mathrm{mg}$; niacin, $34 \mathrm{mg}$; pantothenic acid, $4.0 \mathrm{mg}$; pyridoxine, $3.4 \mathrm{mg}$; thiamin, $3.4 \mathrm{mg}$; riboflavin, $2.8 \mathrm{mg}$; folic acid, $0.6 \mathrm{mg}$; vitamin $\mathrm{E}, 74 \mathrm{mg}$; vitamin $\mathrm{A}, 4.3 \mathrm{mg}$; vitamin $\mathrm{K}_{3}, 1.1 \mathrm{mg}$; Co, $0.28 \mathrm{mg}$; $\mathrm{Cr}, 0.23 \mathrm{mg}$; Se, $0.1 \mathrm{mg}$; biotin, $60 \mu \mathrm{g}$; vitamin $D_{3}, 15.6 \mu \mathrm{g}$; vitamin $B_{12}, 10 \mu \mathrm{g}$

\section{Experimental design and diets}

Study 1. Five cats were adapted to an LP diet (Table 1) for at least 4 weeks, after which they were housed in metabolism cages and the study was commenced. The LP diet was made by adding additional fat, pregelatinised starch, minerals and vitamins to a moist commercial diet (which had passed a minimum feeding protocol for proving an adult maintenance claim for a cat food $\left.{ }^{(11)}\right)$, in order to reduce the protein content (Table 1). After a $9 \mathrm{~d}$ period during which the animals adapted to the metabolism cages (days 1-9), urine was collected quantitatively for $5 \mathrm{~d}$ (days 10-14) and pooled per cat. Thereafter, the cats received the moist HP diet (Table 1) for a further $9 \mathrm{~d}$ (days 15-23) before urine was again collected for $5 \mathrm{~d}$ (days 24-28) and pooled per cat. The calculated metabolisable energy (ME) of both the LP and the HP diets was the same $(20.1 \mathrm{~kJ}(4.8 \mathrm{kcal}) / \mathrm{g} \mathrm{DM})$ as determined using $14.6,35.6$ and $14.6 \mathrm{~kJ} / \mathrm{g} \mathrm{DM}(3.5,8.5$ and $3.5 \mathrm{kcal} / \mathrm{g} \mathrm{DM})$, respectively for protein, fat and carbohydrate. Throughout study 1 , the cats were fed their diets at $125 \%$ of calculated energy requirements $^{(12)}(293 \mathrm{~kJ}(70 \mathrm{kcal}) / \mathrm{kg} \mathrm{BW})$.

Study 2. Ten cats were adapted to the LP diet for at least 2 weeks after which they were transferred to metabolism cages and allowed to adapt for $9 \mathrm{~d}$ before the start of the study. A schematic representation of the dietary treatments of study 2 is provided in Fig. 1. The animals were then randomly allocated into one of two groups based on previous felinine excretion rate. Urine was collected quantitatively for $5 \mathrm{~d}$ and pooled for each cat, after which (day 6), group A received the LP diet supplemented with $0.93 \%$ L-cystine (LPc; Table 1) on days 6-15 and then the LP diet from day 16 to day 23. On day 6 , group B received the LP diet supplemented with cystine, arginine and three (glutamic acid, glycine and proline) dispensable amino acids until day 16 after which they received the LP diet supplemented with $0.93 \%$ L-cystine for $10 \mathrm{~d}$ (days 17-26). From day 27 until day 34, the cats in group B were again fed the LP diet supplemented with cystine, dispensable amino acids and arginine ( $\mathrm{LPc}+\mathrm{D}+$ arg; Table 1). The urine from all of the cats in both groups was individually collected on a daily basis, weighed and a sample frozen until chemical analysis. Each diet was provided ad libitum, with fresh diet being supplied once per $\mathrm{d}$. The dietary compositions are shown in Table 1 . The dietary treatments for groups A and B were carried out concurrently. A heparinised blood sample $(3 \mathrm{ml})$ was obtained from the cats in group A by jugular venepuncture, $3.5 \mathrm{~h}$ after the start of feeding on days 3, 15 and 23 while a blood sample from the cats in group B was taken on days 3, 16, 26 and 34 . A $0.5 \mathrm{ml}$ sample of the blood sample was stored at $-20^{\circ} \mathrm{C}$ while the remainder was centrifuged at $3000 \mathrm{rpm}$ for $10 \mathrm{~min}$.

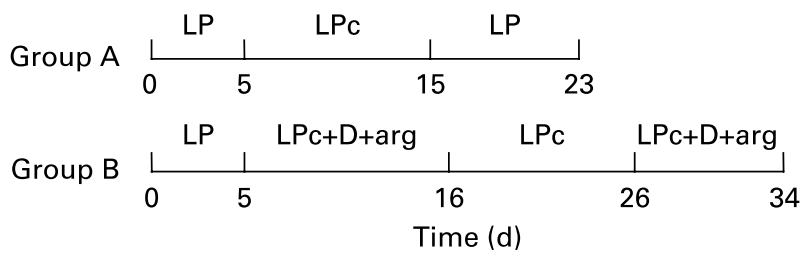

Fig. 1. Schematic representation of the dietary treatments in study 2. LP, low-protein diet; LPc, low-protein diet + cystine; LPC $+D+$ arg, low-protein diet + cystine + dispensable amino acids + arginine. 
The blood plasma was collected and $0.5 \mathrm{ml}$ were ultrafiltered using a Vivaspin 500 concentrator (molecular weight cut-off 5000 Da; Vivascience AG, Hannover, Germany). The plasma and ultrafiltered samples were stored at $-20^{\circ} \mathrm{C}$ until chemical analysis. BW of the cats within each group were recorded on the day of each dietary change.

\section{Chemical analyses}

Urine samples were analysed for specific gravity, felinine, $\mathrm{N}$-acetylfelinine and creatinine, while whole blood samples were analysed for glutathione and ultrafiltered blood plasma samples were analysed for free amino acids and $\gamma$-glutamylfelinylglycine.

Felinine analyses in the urine samples were determined by ion-exchange chromatography utilising post-column $o$-phthalaldehyde derivatisation as described below. Filtered $(0.22 \mu \mathrm{m})$ urine samples were loaded onto a cation-exchange column (Waters Amino Acid Analysis Column P/N 80002) using a Shimadzu LC10A ion-exchange HPLC system (Shimadzu, Kyoto, Japan). Buffer A contained $67 \mathrm{~mm}-$ sodium citrate $(\mathrm{pH} 3.55)$ and $0.1 \%(\mathrm{w} / \mathrm{v})$ phenol, buffer B contained $40 \mathrm{~mm}$-borate $(\mathrm{pH} 9.18)$ and $250 \mathrm{~mm}$-sodium nitrate. Compounds were eluted using a $\mathrm{pH}$ gradient of $100 \%$ buffer A to $80 \%$ buffer B-20\% buffer A in $40 \mathrm{~min}$ at a flow rate of $0.4 \mathrm{ml} / \mathrm{min}$. Felinine was detected using post-column derivatisation with $o$-phthalaldehyde and fluorescence detection, with excitation at $338 \mathrm{~nm}$ and emission at $445 \mathrm{~nm}$. Concentrations were quantified using Shimadzu CLASS-VP 7.2 SP1 Rev B software (Shimadzu, Kyoto, Japan) by comparison of the peak area of felinine in the samples with the peak area of a standard synthetic felinine solution ${ }^{(13)}$.

Free amino acids in the ultrafiltered plasma were measured using a Waters ion-exchange HPLC system (Waters Corporation, Milford, MA, USA) utilising post-column ninhydrin derivatisation and detection at 570 and $440 \mathrm{~nm}$. Peaks were integrated using Millennium32 Chromatography Manager software (Waters Corporation) and levels quantified by comparison of the peak area of amino acids in the samples with the peak area of amino acids in a standard amino acid mixture (Pierce, Rockford, IL, USA).
$N$-acetylfelinine in the filtered $(0 \cdot 22 \mu \mathrm{m})$ urine and $\gamma$-glutamylfelinylglycine in ultrafiltered plasma was measured by reversed-phase HPLC on a Phenomenex Luna C18, $5 \mu \mathrm{m}$ column $(4.6 \times 150 \mathrm{~mm})$, using a Waters HPLC system (Waters Corporation, Milford, MA). A linear 75 min gradient was run, from $100 \%$ solvent I (8.8 mM-trifluoroacetic acid (TFA)) to $100 \%$ solvent II $(8.8 \mathrm{~mm}$-TFA and $21.9 \mathrm{M}$-acetonitrile), which commenced $15 \mathrm{~min}$ after sample injection. $N$-acetylfelinine was detected by absorbance at $214 \mathrm{~nm}$ and peaks integrated using Millennium32 Chromatography Manager software (Waters Corporation). $\mathrm{N}$-acetylfelinine and $\gamma$-glutamylfelinylglycine standards were synthesised as described by Hendriks et al. ${ }^{(2)}$.

Whole blood glutathione was determined using a commercially available kit (Biotech ${ }^{\circledR} \mathrm{GSH}-420^{\mathrm{TM}}$; Oxis International, Portland, OR, USA). Creatinine was determined by a modified Jaffe reaction on a Cobas Fara II analyser (HoffmanLa Roche, Basel, Switzerland) using a Roche diagnostic creatinine kit (catalogue no. 1489291). The kits were used in accordance with the manufacturer's instructions. Specific gravity of the urine samples was determined on a digital refractometer (model UG; Atago Co., Ltd, Itabashi, Tokyo, Japan) after thawing and after the samples reached room temperature, to allow conversion of urine weight to volume.

\section{Statistical analysis}

Paired Student's $t$ tests were used to determine significant differences in selected variables (Table 2) for the cats fed the LP and HP diets. In study 2, all nine measured response variables (Table 3) from each of the two groups of cats were analysed in the first instance using two-way repeatedmeasures ANOVA. Differences between cats were regarded as random effects (variance components) and differences between time periods were tested within cats. Statistical significance was established for probability values below $5 \%$. Validity of the parametric nature of all the ANOVA was confirmed using normal probability plots of the residuals. Where significant differences were established between time periods, orthogonal contrasts were used to determine whether these differences could be meaningfully ascribed to known

Table 2. Body weight (BW), metabolisable energy (ME) intake, felinine excretion, molar felinine:creatinine ratio, molar $N$-acetylfelinine:creatinine ratio and felinine $\mathrm{N}$-acetylation degree of cats fed a low-protein (LP) and high-protein (HP) diet

(Mean values with their standard errors)

\begin{tabular}{|c|c|c|c|c|c|}
\hline \multirow[t]{2}{*}{ Diet ... } & \multicolumn{2}{|c|}{ LP } & \multicolumn{2}{|c|}{$\mathrm{HP}$} & \multirow[b]{2}{*}{$P$} \\
\hline & Mean & SEM & Mean & SEM & \\
\hline $\mathrm{BW}(\mathrm{kg})$ & $3 \cdot 61$ & 0.26 & 3.67 & 0.21 & 0.54 \\
\hline Calculated ME intake (kJ/kg BW per d) & 369 & $12 \cdot 7$ & 356 & 8.5 & 0.24 \\
\hline Calculated ME intake (kcal/kg BW per d) & $88 \cdot 2$ & $3 \cdot 0$ & $85 \cdot 2$ & $2 \cdot 0$ & 0.24 \\
\hline Determined ME intake (kJ/kg BW per d) & 289 & $9 \cdot 9$ & 346 & $8 \cdot 2$ & 0.01 \\
\hline Determined ME intake (kcal/kg BW per d) & $69 \cdot 1$ & $2 \cdot 4$ & $82 \cdot 6$ & $2 \cdot 0$ & 0.01 \\
\hline Felinine excretion $(\mathrm{mg} / \mathrm{d})$ & $51 \cdot 3$ & $10 \cdot 4$ & $39 \cdot 1$ & $7 \cdot 7$ & 0.20 \\
\hline Felinine excretion (mg/kg BW per d) & $14 \cdot 7$ & $3 \cdot 2$ & $10 \cdot 9$ & $2 \cdot 3$ & $0 \cdot 18$ \\
\hline Felinine:creatinine $(\mathrm{mol} / \mathrm{mol})$ & 0.23 & 0.05 & $0 \cdot 16$ & 0.04 & 0.08 \\
\hline $\mathrm{N}$-acetylfelinine:creatinine $(\mathrm{mmol} / \mathrm{mol})$ & $72 \cdot 2$ & $13 \cdot 1$ & $87 \cdot 0$ & $26 \cdot 3$ & 0.50 \\
\hline Felinine $N$-acetylation degree* & 0.26 & 0.05 & 0.32 & 0.07 & 0.57 \\
\hline
\end{tabular}

${ }^{*} \mathrm{~N}$-acetylfelinine/( $\mathrm{N}$-acetylfelinine+free felinine $)$. 
Table 3. Body weight (BW), metabolisable energy (ME) intake, blood plasma concentrations of free cysteine, methionine, arginine and methylbutanol glutathione (MBG), whole blood glutathione concentrations, molar $\mathrm{N}$-acetylfelinine:creatinine ratio and felinine $\mathrm{N}$-acetylation degree of the cats in study 2

(Mean values with their standard errors)

\begin{tabular}{|c|c|c|c|c|c|c|c|c|c|c|c|c|c|c|}
\hline \multirow[t]{3}{*}{ Diet . } & \multicolumn{6}{|c|}{ Diet group A } & \multicolumn{8}{|c|}{ Diet group B } \\
\hline & \multicolumn{2}{|c|}{ LP } & \multicolumn{2}{|c|}{ LPc } & \multicolumn{2}{|c|}{ LP } & \multicolumn{2}{|c|}{ LP } & \multicolumn{2}{|c|}{$\mathrm{LPc}+\mathrm{D}+\arg$} & \multicolumn{2}{|c|}{ LPc } & \multicolumn{2}{|c|}{$\mathrm{LPc}+\mathrm{D}+\arg$} \\
\hline & Mean & SEM & Mean & SEM & Mean & SEM & Mean & SEM & Mean & SEM & Mean & SEM & Mean & SEM \\
\hline BW (kg) & $3.44^{\mathrm{a}}$ & 0.24 & $3.72^{\mathrm{b}}$ & 0.28 & $3.76^{\mathrm{b}}$ & 0.28 & $3.71^{\mathrm{a}}$ & 0.18 & $4 \cdot 17^{\mathrm{b}}$ & 0.23 & $4 \cdot 22^{b}$ & 0.26 & $4 \cdot 16^{\mathrm{b}}$ & 0.26 \\
\hline ME intake (kJ/kg BW per d) & 360 & $20 \cdot 8$ & 379 & $7 \cdot 8$ & 355 & 32.5 & 359 & 17.9 & 385 & $7 \cdot 8$ & 367 & $12 \cdot 5$ & 366 & $23 \cdot 8$ \\
\hline ME intake (kcal/kg BW per d) & $86 \cdot 1$ & $5 \cdot 0$ & 90.5 & 1.5 & 84.9 & 7.8 & 85.9 & $4 \cdot 1$ & $92 \cdot 0$ & 1.9 & 87.8 & $3 \cdot 0$ & 87.5 & $5 \cdot 7$ \\
\hline \multicolumn{15}{|l|}{ Plasma free amino acids (nmol/ml) } \\
\hline Cysteine & $16 \cdot 2^{\mathrm{a}}$ & 4.9 & $32 \cdot 3^{\mathrm{b}}$ & 1.8 & $19 \cdot 1^{a, b *}$ & $2 \cdot 7$ & $17 \cdot 7^{\mathrm{a}}+$ & 2.5 & $25 \cdot 3^{a, b}$ & 6.9 & $31 \cdot 6^{\mathrm{b}}$ & $2 \cdot 3$ & $30 \cdot 2^{b}$ & 3.0 \\
\hline Methionine & $18 \cdot 0$ & 3.0 & $11 \cdot 0$ & 1.7 & $13 \cdot 3$ & $2 \cdot 6$ & $16 \cdot 5^{\mathrm{a}}$ & 2.9 & $8.4^{\mathrm{b}}$ & 1.1 & $13 \cdot 6^{a, b}$ & 1.4 & $10 \cdot 6^{a, b}$ & $1 \cdot 8$ \\
\hline Arginine & ND & ND & ND & ND & ND & ND & $60 \cdot 5^{\mathrm{a}, \mathrm{b}}$ & 9.5 & $95 \cdot 4^{\mathrm{a}} \neq$ & $15 \cdot 8$ & $52 \cdot 7^{\mathrm{b}}$ & $5 \cdot 0$ & $85 \cdot 8^{\mathrm{a}, \mathrm{b} *}$ & $14 \cdot 0$ \\
\hline Whole blood glutathione (nmol/ml) & 40.5 & 7.9 & $52 \cdot 3$ & 3.0 & 54.7 & 14.9 & $84 \cdot 8^{\mathrm{a}}$ & 3.5 & $95 \cdot 5^{\mathrm{a}, \mathrm{b}}$ & $12 \cdot 1$ & $89 \cdot 0^{a, b}$ & 5.9 & $102 \cdot 7^{\mathrm{b}}$ & 4.7 \\
\hline Plasma MBG $(\mathrm{nmol} / \mathrm{ml})$ & $17 \cdot 4^{\mathrm{a}}$ & 3.8 & $26 \cdot 2^{\mathrm{b}}$ & $5 \cdot 6$ & $12 \cdot 2^{\mathrm{a}}$ & 2.5 & $14.8^{\mathrm{a}}$ & 3.8 & $30 \cdot 4^{b}$ & 3.5 & $31.0^{\mathrm{b}}$ & $5 \cdot 0$ & $23 \cdot 0^{a, b} \S$ & 3.8 \\
\hline$N$-acetylfelinine:creatinine $(\mathrm{mmol} / \mathrm{mol})$ & $89.8^{\mathrm{a}}$ & $26 \cdot 3$ & $203 \cdot 0^{\mathrm{b}}$ & 35.8 & $89 \cdot 3^{\mathrm{a}}$ & $25 \cdot 4$ & $60 \cdot 4^{\mathrm{a}}$ & 7.8 & $88 \cdot 9^{\mathrm{a}, \mathrm{b}}$ & $15 \cdot 6$ & $121.5^{\mathrm{b}}$ & 19.4 & $89 \cdot 7^{\mathrm{a}, \mathrm{b}} \mathrm{b}$ & 11.7 \\
\hline Felinine $\mathrm{N}$-acetylation degree\| & 0.28 & 0.06 & 0.29 & 0.04 & 0.25 & 0.03 & 0.20 & 0.02 & 0.18 & 0.02 & 0.20 & 0.03 & 0.20 & 0.01 \\
\hline
\end{tabular}

LP, low-protein; LPc, low-protein + cystine; LPc + D + arg, LPc + dispensable amino acids + arginine; ND, not determined.

Mean values whe lignificantly different $(P<0.05)$.

Value from group A.

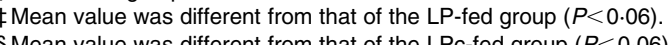

$\mathrm{N}$-acetylfelinine/(N-acetylfelinine + free felinine). 
differences in attributes between the time periods. Tukey's multiple-range tests were used to determine differences between time periods. All data were analysed using Minitab (Minitab Inc., State College, PA, USA) and values are expressed as mean values with their standard errors unless otherwise stated.

\section{Results}

\section{Study 1}

The cats consumed all their allocated food each day with the exception of one cat on the LP diet which consumed on average only $86 \%$ of the allocated diet. The intake of cystine + methionine (cys + met) of the cats when fed the LP and HP was 0.10 (SEM 0.01) and 0.26 (SEM 0.01) g/kg BW per d respectively. The BW at the start $(3.61 \mathrm{~kg})$ and end $(3.53 \mathrm{~kg})$ of the $5 \mathrm{~d}$ collection period of the cats fed the LP diet were significantly $(P=0.04)$ different. For cats fed the HP diet, there was no significant change in BW over the collection period $(3.67 v .3 .61 \mathrm{~kg})$ (Table 2). Subsequent determination of the ME of both diets, in vivo revealed that the HP (unmodified moist diet) and LP diets contained an ME of 20.2 and $16.3 \mathrm{~kJ} / \mathrm{g} \mathrm{DM}(4.83$ and $3.90 \mathrm{kcal} / \mathrm{g} \mathrm{DM})$, respectively.

The results of study 1 are presented in Table 2 . All cats remained healthy throughout the study. Using the 'in vivo determined' $\mathrm{ME}$, there was a significant $(P<0.01)$ difference in the ME intake. Felinine excretion was $14.7 \mathrm{mg} / \mathrm{kg} \mathrm{BW}$ per $d$ when the cats were fed the LP diet and $10.9 \mathrm{mg} / \mathrm{kg}$ BW per $d$ when fed the HP diet $(P<0 \cdot 18)$. There was a trend $(P<0.08)$ towards a lower felinine:creatinine ratio (0.16 (SEM 0.04) v. 0.23 (SEM 0.05)) when the cats were fed the HP diet compared with the LP diet; however, there was no significant difference in the molar $\mathrm{N}$-acetylfelinine:creatinine ratio between cats fed the HP and LP diets. The degree of $\mathrm{N}$-acetylation of felinine $(\mathrm{N}$-acetylfelinine/( $N$-acetylfelinine + free felinine $))$ was not significantly different between the LP and HP diets (0.26 (SEM 0.05) v. $0 \cdot 32$ (SEM 0.07), respectively).

\section{Study 2}

All cats remained healthy throughout the study. The results of study 2 are presented in Table 3 and Figs. 2 and 3. There was a significant $(P<0 \cdot 001)$ effect of dietary treatment over time on the $\mathrm{BW}$ of the cats in both groups, with the mean BW of the cats within each group being lower $(P<0.001)$ when the LP diet was initially fed compared with the other periods. Significant differences in BW could be ascribed not only to dietary differences $(P<0.04)$ but also to differences between the first LP feeding period and the second $(P<0 \cdot 01)$. There was no significant effect of dietary treatment over time on the ME intake of the cats within either group.

The initial mean urinary felinine excretion of the cats fed the LP diet (group A) was $57.5 \mathrm{mg} / \mathrm{d}$ and this increased over $10 \mathrm{~d}$ when cystine was added to the diet to $94.5 \mathrm{mg} / \mathrm{d}$ (Fig. 2). When cystine was removed from the diet, daily urinary felinine excretion decreased exponentially to a concentration $(52.9 \mathrm{mg} / \mathrm{d})$ not significantly different from that recorded at the start of the study. When expressed per unit creatinine, felinine excretion showed a linear increase

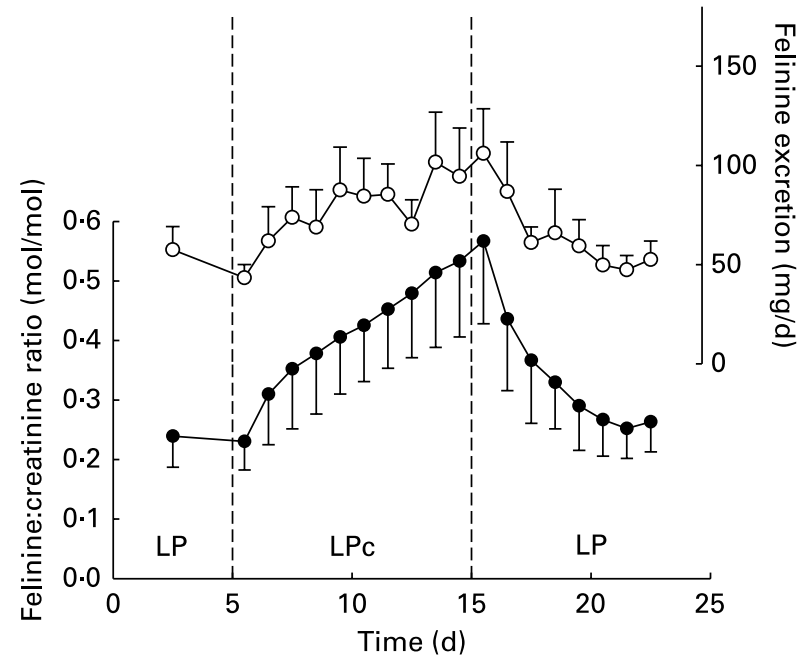

Fig. 2. Daily urinary felinine $(O)$ and felinine:creatinine ratio $(\bullet)$ of intact male cats fed a low-protein diet (LP) and the low-protein diet + cystine (LPC). Values are means, with standard errors represented by vertical bars.

$(P<0.05)$ from 0.24 (SEM 0.05) over the $5 \mathrm{~d}$ baseline period to 0.53 (SEM 0.13 ) mol $/ \mathrm{mol}$ after $10 \mathrm{~d}$ cystine dietary supplementation (Fig. 2). Following the removal of cystine supplementation, the felinine:creatinine ratio showed an exponential decrease (day 15 onwards) and returned to a ratio $(0.26 \mathrm{~mol} / \mathrm{mol})$ similar to that of the baseline period.

There was a significant $(P<0.03)$ effect of dietary treatment over time on plasma free cysteine concentrations, which approximately doubled from $16 \cdot 2$ (SEM 4.9 ) $\mathrm{nmol} / \mathrm{ml}$ before L-cystine supplementation to $32 \cdot 3$ (SEM 1.8) with supplementation $(P<0.03)$. After the removal of dietary L-cystine, the plasma free cysteine concentration dropped to 19.1 (SEM 3.8) $\mathrm{nmol} / \mathrm{ml}$ (Table 3), a value not significantly different to the initial LP value (Table 3). Numerically, plasma free methionine decreased $39 \%$ (18.0 (SEM 3.0) v. 11.0 (SEM 1.7) $\mathrm{nmol} / \mathrm{ml}$ ) with the addition of dietary L-cystine, and then increased by $21 \%$ to $13 \cdot 3$ (SEM $2 \cdot 6$ ) $\mathrm{nmol} / \mathrm{ml}$ when L-cystine was omitted from the diet. However, these differences were not significant. There was a significant $(P<0.02)$ effect of dietary treatment over time on plasma free arginine concentrations, which increased $62 \%$ following the addition of L-cystine, and then decreased again to concentrations which were not significantly different from those at the start of the study when the LP diet was being fed.

Dietary supplementation with cystine and its subsequent removal did not result in any significant change in whole blood glutathione concentrations. There was an effect $(P<0.05)$ of dietary treatment over time on plasma MBG, which increased $(P<0.05) 37 \%$ when cystine was added to the diet (from 17.4 (SEM 3.8) to 26.2 (SEM 5.6) $\mathrm{nmol} / \mathrm{ml}$ ) and significantly decreased $(P<0.05)$ to approximately half this concentration (12.2 (SEM 2.5) $\mathrm{nmol} / \mathrm{ml}$ ) after L-cystine was removed from the diet (Table 3 ). The molar urinary $\mathrm{N}$-acetylfelinine:creatinine ratio significantly $(P<0.001)$ increased over the course of the study to more than double (89.8 (SEM 26) v. 203.0 (SEM 35.8) $\mathrm{mmol} / \mathrm{mol}$, respectively; $P<0.001)$ with the addition of L-cystine to the diet and returned to $89 \cdot 3$, a value not significantly different from the initial LP value, after L-cystine removal from the diet. 
However, there was no effect of dietary treatment over time on the degree of felinine $N$-acetylation, which remained relatively constant between 0.25 to 0.29 throughout the \pm L-cystine periods, despite the more than doubling of free felinine following dietary cystine supplementation.

In study 2 , the initial total daily urinary felinine excretion of the cats in group B fed the LP diet (Fig. 3) was not different from the felinine excretion of the cats in group A (49.6 and $57.5 \mathrm{mg} / \mathrm{d}$, respectively). When L-cystine plus dispensable amino acids plus arginine were added to the diet, the average daily urinary felinine excretion of the cats in group B increased linearly until day 16 . The felinine:creatinine ratio showed a similar pattern (Fig. 3) to that of the daily urinary excretion. When the dispensable amino acids and arginine were removed from the diet on day 17 , the daily urinary felinine excretion and the felinine:creatinine ratio increased by 31 and $44 \%$, respectively. The mean daily felinine excretion and the urinary felinine:creatinine ratio between days 16 (LPc + $\mathrm{D}+\arg )$ and 17 (LPc) were significantly $(P<0.05)$ different. Over the $10 \mathrm{~d}$ during which the LPc diet was fed (days 17-26), the daily felinine excretion recorded a maximum value of $144 \mathrm{mg} / \mathrm{d}$ on day 18 and remained relatively constant until day 26. The felinine:creatinine ratio showed a gradual decrease over the $10 \mathrm{~d}$ LPc feeding period. When the dispensable amino acids plus arginine mixture was again added to the diet on day 27 , the daily urinary felinine excretion of the cats rapidly decreased to concentrations recorded when the same diet was fed earlier (day 16). The urinary felinine:creatinine ratio also decreased after the dispensable amino acids plus arginine mixture was added to the diet, but the decrease was more gradual compared with the daily felinine excretion. The felinine:creatinine ratio at the end of the study (day 34) was not significantly different from the ratio recorded at the end of the previous period when the same diet (day 16: $\mathrm{LPc}+\mathrm{D}+\mathrm{arg})$ was fed $(0.37$ and $0.41 \mathrm{~mol} /$ mol, respectively).

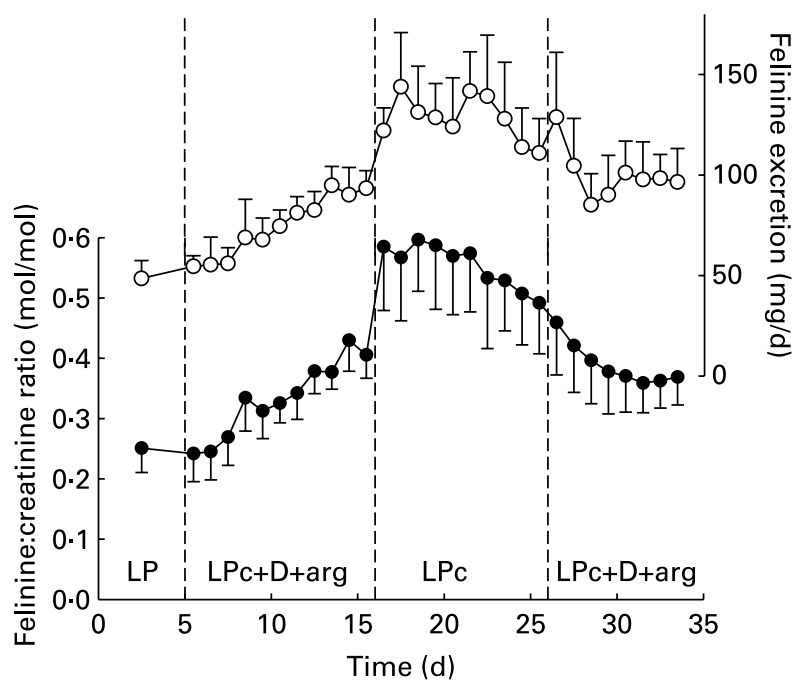

Fig. 3. Daily urinary felinine $(O)$ and felinine:creatinine ratio $(\bullet)$ of intact male cats fed a low-protein diet (LP) and the low-protein diet + cystine (LPC) and the low-protein diet + cystine + dispensable amino acids + arginine $(\mathrm{LPC}+\mathrm{D}+\mathrm{arg})$. Values are means, with standard errors represented by vertical bars.
The first blood samples (day 2.5) for four of the cats in group B were inadvertently not ultrafiltered within $1 \mathrm{~h}$ after collection, which is known to affect plasma free cysteine values $^{(14)}$. Free cysteine values for these four cats at day 2.5 were calculated based on the proportion of free cysteine to total free amino acids of the cats in group A. When cystine plus dispensable amino acids plus arginine $(\mathrm{LPc}+\mathrm{D}+\arg )$ were added to the LP diet of group $\mathrm{B}$, there was a trend for plasma free cysteine to increase $(P=0.09)$ from 17.7 (SEM $2 \cdot 5$ ) to $25 \cdot 3$ (SEM 6.9) $\mathrm{nmol} / \mathrm{ml}$ (Table 3 ). When the dispensable amino acids plus arginine were removed and the LPc diet was fed, plasma free cysteine was significantly higher (31.6 (SEM 2.3) nmol/ml; $P<0.05$ ) compared with when the LP diet was fed. When the dispensable amino acids plus arginine were again added to the diet, the plasma free cysteine remained at a similar level $(30 \cdot 2(\operatorname{SEM~} 3 \cdot 0) \mathrm{nmol} / \mathrm{ml})$ to that when the LPc diet was fed.

There was also an effect $(P<0.02)$ of dietary treatment over time on plasma free methionine concentrations. The LP diet supplemented with cystine plus dispensable amino acids plus arginine resulted in a decrease $(P<0.02)$ in plasma free methionine concentrations from 16.5 (SEM 2.9) to 8.4 (SEM $1.1) \mathrm{nmol} / \mathrm{ml}$ which then returned to intermediate values of 13.6 (SEM 1.4) and 10.6 (SEM 1.4) $\mathrm{nmol} / \mathrm{ml}$ when the LPc and $\mathrm{LPc}+\mathrm{D}+\arg$ diets were fed respectively. Effects of the dietary supplementations over time were also found for the plasma concentration of free arginine $(P<0.01)$ which increased $(P=0.051)$ from 60.5 (SEM 9.5) to 95.4 (SEM 15.8) $\mathrm{nmol} / \mathrm{ml}$ when dispensable amino acids, cystine and arginine were added to the LP diet, and significantly decreased $(P<0.017)$ to $52.7($ SEM 5.0$) \mathrm{nmol} / \mathrm{ml}$ as a result of omitting the dispensable amino acids and arginine from the diet. Reintroducing dispensable amino acids and arginine to the diet containing L-cystine resulted in an increase $(P=0.066)$ in plasma free arginine to 85.8 (SEM $14 \cdot 0$ ) $\mathrm{nmol} / \mathrm{ml}$.

The mean whole blood glutathione concentrations of the cats were numerically higher when fed the LPC $+\mathrm{D}+\arg$ and LPc diets compared with the values recorded during the feeding of the LP diet, with a significant difference $(P<0.01)$ being recorded during the last time period when the LPC $+\mathrm{D}+\arg$ diet was fed. Interestingly the whole blood glutathione concentrations recorded for group B were consistently higher compared with the values recorded by the cats in group A.

Plasma MBG increased $(P<0.01)$ from 14.8 (SEM 3.8) to $30.4(\mathrm{SEM} 3.5) \mathrm{nmol} / \mathrm{ml}$ with the addition of dispensable amino acids, cystine and arginine to the LP diet. Withdrawal of the dispensable amino acids and arginine from the diet did not change the plasma MBG concentrations; however, there was a trend $(P<0.06)$ for a decrease following the reintroduction of dispensable amino acids and arginine to the diet. The molar $N$-acetylfelinine:creatinine ratio was affected by dietary supplementation over time $(P<0 \cdot 01)$ and showed the highest value when the LPc diet was fed to the cats. The urinary ratio was not different between the two periods when the $\mathrm{LPC}+\mathrm{D}+\arg$ diet was fed (88.9 (SEM 15.6) v. 89.7 (SEM 11.7) $\mathrm{mmol} / \mathrm{moL} ; P=0.48$ ) but was significantly increased $(P<0.01)$ when the LPc diet was fed compared with when the LP diet alone was fed. There was no effect of dietary supplementation over time on the molar $N$-acetylfelinine:total felinine ratio, which remained relatively constant between $0 \cdot 18$ and 0.20 . 


\section{Discussion}

Previous studies have shown that cysteine and methionine are precursors for the synthesis of felinine, with cysteine being the more immediate precursor of the two ${ }^{(8)}$. In 1959 , Avizonis \& Wriston ${ }^{(7)}$ reported an increase in urinary felinine concentration (from 1.5 to over $8 \mathrm{~g} / \mathrm{l}$ ) in an intact male cat following supplementation of a diet of unknown composition with $1 \%$ L-cystine. In contrast, in the present study when fed LP and HP diets, the intact adult male cats excreted similar amounts of felinine $(14.7 v .10 .9 \mathrm{mg} / \mathrm{kg}$ BW per d, respectively) (Table 2), despite the cats ingesting 2.6 times more cys + met on the HP diet compared with the LP diet. It can be calculated from body composition data ${ }^{(15)}$ that the additional cys + met that could potentially become available for felinine synthesis from endogenous origin due to the catabolism of body protein by the cats fed the LP diet would be insignificant compared with the total daily dietary cys + met intake. Consistent with the urinary felinine excretion, the molar ratios of felinine and $\mathrm{N}$-acetylfelinine per unit creatinine excreted by the cats also did not differ when fed the LP and HP diets, nor did the degree of felinine $N$-acetylation.

There are several possible explanations for why an increase in dietary protein did not result in an increase in felinine and $\mathrm{N}$-acetylfelinine excretion. Since the amino acid composition relative to lysine was identical between the LP and HP diets, it is possible that felinine synthesis may be affected by dietary concentrations of certain amino acids (or combination thereof) in addition to total sulfur amino acid intake. Alternatively, there may have been an effect of the addition of starch, lard and vitamins and minerals to the HP diet on felinine excretion. In addition, the ingredients used in the manufacture of the HP diet may contain substances that can modulate or interfere with felinine synthesis and excretion. Although this may be a possible explanation for the results of study 1 as the levels of inclusion were different between the HP and LP diets, the inclusion level in study 2 was equal among dietary treatments. Another possibility is that since there was a 2 -week time difference between the urine collection periods there may have been an effect of season. There are no studies reporting the effect of season on felinine excretion in adult male cats, making it difficult to gauge any possible impact of season on the results. It appears from study 1 that the regulation of felinine synthesis in cats is more complex than indicated by the study of Avizonis \& Wriston ${ }^{(7)}$, since felinine excretion did not simply increase with an increased dietary concentration of the immediate precursors (cys + met) for MBG synthesis.

In study 2 we examined under more controlled conditions, and with the cats having ad libitum access to food, the effect of both cystine supplementation and additional dispensable amino acids (glutamic acid, glycine, proline) on urinary felinine excretion. The rationale was that since MBG is hydrolysed in the kidney to release felinine, and with glutathione being a precursor to $\mathrm{MBG}^{(4)}$, additional dispensable amino acids might increase tissue glutamine ${ }^{(16,17)}$ and thus increase felinine synthesis if cysteine is not already limiting. Arginine was added to the diet to prevent hyperammonaemia that might have occurred when dietary protein $/ \mathrm{N}$ is high and arginine is $\operatorname{limiting}^{(18)}$.
The addition of $0.93 \%$ L-cystine to the LP diet of the cats (group A) in study 2 resulted in a significant increase in the concentrations of plasma free cysteine from 16.2 to $32.3 \mathrm{nmol} / \mathrm{ml}$. Urinary felinine and $N$-acetylfelinine (Fig. 3, Table 3) also increased approximately 2-fold over a $10 \mathrm{~d}$ period when the LP diet was supplemented with cystine and decreased again after cystine withdrawal. This effect was also observed in group $\mathrm{B}$ where an approximate 2-fold increase in felinine:creatinine ratio $(0.25$ v. $0.58 \mathrm{~mol} / \mathrm{mol})$ was recorded between the LP and LPc diet. In both studies, baseline ratios $(0.24 v .0 .25 \mathrm{~mol} / \mathrm{mol})$ were similar when the LP diet was fed as well as the maximum ratios recorded $(0.53$ v. $0.60 \mathrm{~mol} / \mathrm{mol})$ when the LPc diet was fed. A direct comparison between the increase in felinine observed in the present study to that reported by Avizonis \& Wriston ${ }^{(7)}$ may be misleading, as only urinary concentration and not urine volume or total daily felinine output or creatinine was reported by the latter authors.

Sulfur amino acid supplementation or increased dietary content of total sulfur amino acids is known to increase blood glutathione levels in cats ${ }^{(6)}$, rats ${ }^{(19)}$ and human subjects ${ }^{(20)}$. Fettman et $a l^{(6)}$ reported that dietary supplementation of cystine resulted in an increase in both reduced and oxidised blood glutathione concentrations in castrated male and female cats. In the present study, whole blood glutathione concentrations were unchanged following the addition and withdrawal of cystine from the diet. However, there was a significant increase in plasma MBG (which is synthesised from glutathione) and subsequent decrease with the withdrawal of cystine from the diet. The latter indicates that overall, hepatic glutathione synthesis must have increased due to cystine supplementation, resulting in an increase in urinary felinine and $\mathrm{N}$-acetylfelinine excretion. The activity of the rate-limiting enzyme in glutathione synthesis, glutamate cysteine ligase, has been shown to increase upon cysteine supplementation in rats ${ }^{(21,22)}$. It appears that for intact male cats, the substrate (glutathione) is rate limiting whereas the work of Fettman et $a l^{(6)}$ indicates that in castrates (and intact females) the glutathione sulfur transferase may be rate limiting for MBG synthesis, thus resulting in different effects of dietary cystine addition. This effect in castrates is probably due to hormonal differences, as we have recently shown that testosterone administration to females and castrated male cats results in a significant increase in plasma MBG concentrations and felinine and $N$-acetylfelinine excretion ${ }^{(3)}$.

Using data for kittens ${ }^{(23)}$, the plasma amino acid data (Table 3 , group $\mathrm{A}$ and $\mathrm{B}$, and not shown) indicate that total sulfur amino acids were the most limiting essential amino acids in the LP diet together possibly with threonine, lysine and arginine. Compared with normal concentrations of plasma amino acids for kittens ${ }^{(23)}$, plasma dispensable amino acids of the cats when fed the LP diet were at normal $(102 \%)$ to high concentrations $(317 \%)$, indicating that in this diet, essential amino acids and not $\mathrm{N}$ was limiting overall protein anabolism. Further evidence that sulfur amino acids were the most limiting essential amino acids in the LP diet is indicated by the numerical decrease in plasma free methionine following cystine supplementation of the LP diet. This is consistent with the observations of Strieker et $a l^{(24)}$ who reported a numerical decrease (10 to $4 \mathrm{nmol} / \mathrm{ml})$ in the free plasma methionine concentration in kittens after cystine addition to 
a methionine-deficient diet. This effect is thought to be due to the stimulation of protein synthesis by the addition of cystine, whereby methionine becomes more limiting due to partitioning to tissues with higher priority and higher protein turnover, thereby resulting in a decrease in plasma free methionine ${ }^{(24)}$. Consistent with this view, in the present study, increases in BW were observed after a long adaptation period on the LP diet when cystine was added to the diet, while ME intake remained unchanged. Plasma free arginine increased when cystine was added to the LP diet from 32.8 (SEM 4.8) to $53 \cdot 1$ (SEM 5.1) $\mathrm{nmol} / \mathrm{ml}$ and decreased again to 38.9 (SEM 4.1) $\mathrm{nmol} / \mathrm{ml}$, when cystine was removed from the diet of the cats. Arginine plays an integral role in maintaining the urea cycle and the reduced amino acid catabolism when fed the LP diet may have spared arginine.

In study 2 , as expected, the plasma free arginine concentration increased as a result of arginine addition to the LP diet and decreased following withdrawal of arginine from the diet. In both studies the baseline felinine:creatinine ratios $(0.24$ v. $0.25 \mathrm{~mol} / \mathrm{mol})$ were similar at the start of the study. Using linear regression analysis, the average daily increase in the felinine:creatinine ratio when the LPc $+\mathrm{D}+\arg$ diet was fed was only $59.6 \%$ of that observed when the LPc diet was fed. Following withdrawal of dispensable amino acids and arginine from the diet, the urinary free felinine:creatinine ratio increased sharply (Fig. 3) from 0.41 (SEM 0.04) to 0.58 (SEM 0.11$) \mathrm{mol} / \mathrm{mol}(P<0.05)$, a concentration which was similar to that observed for the LPc group in study 1 (Fig. 2). Thus, the inclusion of one or a combination of amino acids appeared to inhibit felinine synthesis (through MBG) or excretion. Reintroduction of the dispensable amino acids plus arginine to the diet did not result in a sudden decrease in the felinine:creatinine ratio, although a drop in daily felinine excretion was observed.

It is possible that the above effect was due to the withdrawal of one or more of the amino acids (glutamic acid, glycine, proline or arginine) from the diet. It is tempting to postulate that the increase in the felinine:creatinine ratio was a result of the withdrawal of arginine from the diet rather than the dispensable amino acids. Arginine addition may cause partial inhibition of glutathione sulfur transferase, the enzyme responsible for synthesis of the felinine precursor MBG, either at the enzyme level through nitrosylation of tyrosine and/or sulfydryl residues ${ }^{(25-28)}$ or at the transcription level ${ }^{(29)}$ as a result of arginine being a precursor of $\mathrm{NO}^{(30)}$. Another possibility, although we believe less likely, is that MBG biosynthesis may have remained constant and the apparent decrease in urinary felinine following supplementation with arginine may be the result of a decrease in the degradation of the tripeptide via inhibition of $\gamma$-glutamyl transferase or dipeptidase activities. These hypotheses, although plausible, remain tentative until the appropriate experiments have been conducted.

Unfortunately, blood samples were only taken at the end of each dietary treatment, therefore there is no plasma MBG value available which correlates with the high felinine:creatinine ratio observed the day after the amino acids were withdrawn from the diet. Following this, the felinine:creatinine ratio slowly decreased over the ensuing $9 \mathrm{~d}$ period until the next blood sample was taken. Plasma values and $N$-acetylfelinine values (Table 3 ) therefore relate to the final day when the
LPc diet was fed and when the felinine:creatinine ratio had decreased to 0.49 (SEM 0.08 ) $\mathrm{mol} / \mathrm{mol}$, making it difficult to deduce whether MBG synthesis or degradation was affected by the dietary supplementation.

It is interesting to note that although free felinine varied more than 2 -fold during study 2 , the molar $N$-acetylfelinine:total felinine ratio varied by no more than $10 \%(0 \cdot 18-0.20)$, indicating that the $N$-acetyl transferase enzyme was not saturated under these experimental conditions. There was, however, a difference in the degree of felinine $N$-acetylation between the two groups in study 2, with group A having higher values than group B. There does appear to be significant animal-to-animal variation in the degree of felinine $\mathrm{N}$-acetylation (for example, group A, day 2.5, 0.15-0.46), which most probably accounts for this difference.

In summary, we have demonstrated that dietary supplementation with free cystine, but not dietary $\mathrm{N}$, results in an increase in excretion of felinine and $\mathrm{N}$-acetylfelinine by intact male cats. Supplementation with dispensable amino acids plus arginine plus cystine resulted in a lower than expected increase in felinine excretion compared with a diet supplemented with cystine alone. This raises the possibility that one or more of these amino acids is causing an inhibition of either MBG synthesis or degradation, either of which would result in decreased felinine excretion. Arginine is discussed as the amino acid which is most likely to be having a negative effect on the synthesis of MBG via inhibition of glutathione sulfur transferase through the NO pathway.

\section{Acknowledgements}

We thank Ms M. McGrath for the analysis of felinine and $\mathrm{N}$-acetylfelinine, the late Dr P. Pearce for glutathione analysis and Ms K. O'Flaherty for the care of the animals. The present study was supported by the Centre for Feline Nutrition, Massey University, Palmerston North, New Zealand.

All authors were involved in analysing the dataset, reviewing and interpreting the results and writing the manuscript. The first author declares there to be no apparent conflict of interest.

Part of this work was presented at the Nestlé Purina Forum of 14-17 October 2004 at St Louis, MO, USA and has been published as an abstract ${ }^{(31)}$.

\section{References}

1. Hendriks WH, Tarttelin MF \& Moughan PJ (1995) Twenty-four hour felinine excretion pattern in entire and castrated cats. Physiol Behav 58, 467-469.

2. Hendriks WH, Harding DRK \& Rutherfurd-Markwick KJ (2004) Isolation and characterization of $\gamma$-glutamylfelinylglycine breakdown products in the urine of the domestic cat (Felis catus). Comp Biochem Physiol B 139, 245-251.

3. Hendriks WH, Rutherfurd-Markwick KJ, Weidgraaf K, Ugarte C \& Rogers QR (2008) Testosterone increases urinary free felinine, $N$-acetylfelinine and methylbutanolglutathione excretion in cats (Felis catus). J Anim Physiol Anim Nutr 92, 53-62.

4. Rutherfurd KJ, Rutherfurd SM, Moughan PJ \& Hendriks WH (2002) Isolation and characterisation of a felinine containing peptide from the blood of the domestic cat (Felis catus). J Biol Chem 277, 114-119. 
5. Miyazaki M, Yamashita T, Suzuki Y, Salto Y, Soeta S, Tiara H \& Suzuki A (2006) A major urinary protein of the domestic cat regulates the production of felinine, a putative pheromone precursor. Chem Biol 13, 1071-1079.

6. Fettman MJ, Valerius KD, Ogilvie GK, Bedwell CL, Richardson KL, Walton JA \& Hamar DW (1999) Effects of dietary cysteine on blood sulphur amino acid, glutathione, and malondialdehyde concentrations in cats. Am J Vet Res 60, 328-333.

7. Avizonis PV \& Wriston JC Jr (1959) On the biosynthesis of felinine. Biochim Biophys Acta 34, 279-281.

8. Hendriks WH, Rutherfurd SM \& Rutherfurd KJ (2001) Incorporation of ${ }^{35} \mathrm{~S}$-methionine, ${ }^{35} \mathrm{~S}$-cysteine and ${ }^{35} \mathrm{~S}$-sulphate into felinine. Comp Biochem Physiol 129, 211-216.

9. Hendriks WH, Wamberg S \& Tarttelin MF (1999) A metabolism cage for quantitative urine collection and accurate measurements of water balance in adult cats (Felis catus). J Anim Physiol Anim Nutr 82, 94-105.

10. Anonymous (2003) Code of Ethical Conduct for the Use of Live Animals for Teaching and Research, revised ed., Palmerston North, New Zealand: Massey University.

11. Association of American Feed Control Officials (2004) Official Publication of the Association of American Feed Control Officials Inc. Atlanta, GA: AAFCO.

12. National Research Council (1986) Nutrient Requirements of Cats. Washington, DC: National Research Council, National Academy Press.

13. Hendriks WH, Woolhouse AD, Tarttelin MF \& Moughan PJ (1995) Synthesis of felinine, 2-amino-7-hydroxy-5,5-dimethyl4-thiaheptanoic acid. Bioorg Chem 23, 89-100.

14. Torres CL, Miller JW \& Rogers QR (2004) Determination of free and total cyst(e)ine in plasma of dogs and cats. Vet Clin Pathol 33, 228-233.

15. Hendriks WH, Moughan PJ \& Tarttelin MF (1997) Body composition of the adult domestic cat. J Anim Physiol Anim Nutr 77, $16-23$.

16. Cao Y, Feng Z, Hoos A \& Klimberg VS (1998) Glutamine enhances gut glutathione production. JPEN J Parenter Enteral Nutr 22, 224-227.

17. Yu JC, Jiang AM \& Li DM (1999) Glutamine: a precursor of glutathione and it effect on liver. World J Gastroenterol 5, $143-146$

18. Morris JG \& Rogers QR (1978) Ammonia intoxication in the near-adult cat as a result of a dietary deficiency of arginine. Science 199, 431-432.

19. Mariotti F, Simbelie KL, Makarios-Lahham L, Huneau JF, Laplaize B, Tome D \& Even PC (2004) Acute ingestion of dietary proteins improves post-exercise liver glutathione in rats in a dose dependent relationship with their cysteine content. J Nutr 134, 128-131.

20. Badaloo A, Reid M, Forrester T, Heird WC \& Jahoor F (2002) Cysteine supplementation improves the erythrocyte glutathione synthesis rate in children with severe edematous malnutrition. Am J Clin Nutr 76, 646-652.

21. Cresenzi CL, Lee JI \& Stipanuk MH (2003) Cysteine is the metabolic signal responsible for dietary regulation of hepatic cysteine dioxygenase and glutamate cysteine ligase in intact rats. J Nutr 133, 2697-2702.

22. Lee JI, Londono M, Hirschberger LL \& Stipanuk MH (2004) Regulation of cysteine dioxygenase and $\gamma$-glutamylcysteine synthetase is associated with hepatic cysteine level. J Nutr Biochem 15, 112-122.

23. Zicker SC \& Rogers QR (1990) Use of plasma amino acid concentrations in the diagnosis of nutritional and metabolic diseases in veterinary medicine. In Proceedings of IVth Congress of International Society for Animal Clinical Biochemistry, 18-21 July, pp. 107-121 [JJ Kaneko, editor]. Davis, CA: University of California, Davis.

24. Strieker MJ, Werner A, Morris JG \& Rogers QR (2006) Excess dietary cystine intensifies the adverse effects of a methionine deficient diet in the cat. $J$ Anim Phys Anim Nutr 90, 440-445.

25. Lee WI \& Fung HL (2003) Mechanism-based partial inactivation of glutathione S-transferases by nitroglycerin: tyrosine nitration $v s$ sulfhydryl oxidation. Nitric Oxide 8, 103-110.

26. Ji Y \& Bennett BM (2003) Activation of microsomal glutathione S-transferase by peroxynitrite. Mol Pharmacol 63, $136-146$

27. Ji Y, Toader V \& Bennett BM (2002) Regulation of microsomal and cytosolic glutathione S-transferase activities by S-nitrosylation. Biochem Pharmacol 63, 1397-1404.

28. Wong PSY, Eiserich JP, Reddy S, Lopez EL, Cross CE \& van der Vleit A (2001) Inactivation of glutathione S-transferases by nitric oxide-derived oxidants: exploring a role for tyrosine nitration. Arch Biochem Biophys 394, 216-228.

29. Hayes JD, Flanagan JU \& Jowsey IR (2005) Glutathione transferases. Anпu Rev Pharmacol Toxicol 45, 51-88.

30. Can C, Sen S, Boztok N \& Tuglular I (2000) Protective effect of oral L-arginine administration on gentamycin-induced renal failure in rats. Eur J Pharmacol 390, 327-334.

31. Hendriks WH, Rutherfurd-Markwick KJ, Weidgraaf $\mathrm{K}$ \& Rogers QR (2005) The effect of nitrogen, cystine and isovaleric acid on urinary excretion of felinine and isovalinine in male cats. Comp Cont Educ Pract Vet 27, Suppl., 86. 